\title{
Application of Copper Nano Particles in Antimicrobial Packaging: A Mini Review
}

\section{Nafiseh Zamindar ${ }^{1 *}$, Ensieh Sadat Anari ${ }^{1}$, Sara Sadat Bathaei ${ }^{2}$, Nadia Shirani ${ }^{1}$, Leila Tabatabaei ${ }^{2}$, Negin Mahdavi-Asl ${ }^{2}$, Ali Khalili ${ }^{3}$ and Saeed Paidari $^{2}$}

${ }^{1}$ Department of Food Science and Technology, Isfahan (Khorasgan) Branch, Islamic Azad University, Isfahan, Iran

${ }^{2}$ Department of Food Science and Technology, Science and Research Branch, Islamic Azad University, Tehran, Iran

${ }^{3}$ Department of Chemistry, Science and Research Branch, Islamic Azad University, Isfahan, Iran

*Corresponding Author: Nafise Zamindar, Associate Professor, Department of Food Science and Technology, Isfahan (Khorasgan) Branch, Islamic Azad University, Isfahan, Iran.
Received: March 26, 2020

Published: April 22, 2020

(C) All rights are reserved by Nafiseh

Zamindar., et al.

\section{Abstract}

Nowadays, application of antimicrobial packaging is extended due to increasing infections and bacterial contaminations transferred by foodstuff. Among different NPs silver, copper and gold are the most implemented antibacterial NPs used in the field of food industry. Researchers have used Copper nanoparticles as antimicrobial agent due to its lower price, simple synthesizes and its nutraceutical properties rather than silver NPs in some cases. Since, application of NPs in different packaging may exert some effects on animal and human cells, legislative authorities determined some rules for measurement of NPs migration to food material. Therefore, numerous researchers measured migration of copper NPs to foodstuff using Atomic Adsorption ICPMS and etc. In the current study different aspects of application of Copper nanoparticles as antibacterial packaging namely migration, antibacterial properties and instrumentation have been discussed.

Keywords: Copper Nanoparticle; CuNPs; Nanopackaging; Antimicrobial; Migration

\section{Introduction}

Packaging is aimed to preserve quality and texture, prevent bacterial, chemical and physical contamination as well as a consumer friendly appearance [1]. For a better physical protection, packaging should be flexible enough and also resistant to corrosion and abrasion. Moreover, permeability to oxygen, $\mathrm{CO}_{2}$, water vapor should be low enough to protect food material in a safe situation [2].

Paper, glass, aluminum, steel and plastics are among usual packaging material in food industry [3]. In past few decades oil based plastics have been remarkably considered as the most used packaging materials due to their low price, ease of production as well as high strength [4-6]. According to a survey, implementation of packaging increases 7\% annually [7] and just 5\% of this huge amount recycles that leads to increment of plastic residues in environment and finally human health risk and diseases may enhance $[8,9]$. In recent years, although application of biodegradable packaging had an increasing trend, there have been some limitations for its wide spread application due to its high price, high permeability to oxygen and its brittle characteristics. For instance, starch, as a polysaccharide thermoplastic polymer have been used as substituent of plastic polymers however there have been limitations due to its low mechanical strength, sensitivity to humidity and brittleness occurred by amylose crystallization $[10,11]$. Numerous methods have been suggested for surmounting this issue such as coating the surface of film using preventing substances, increasing crystallization degree as well as application of nanoparticles $[12,13]$. According to the recent research, one of the most effective ways to address this issue is application of nanoparticles in packaging $[14,15]$. Nanoparticles (NPs) such as Silver, Gold, Copper, $\mathrm{TiO}_{2}, \mathrm{ZnO}$ have reported to increase thermal and mechanical properties $[16,17]$ improve gas barrier properties [18] and exert antimicrobial effects [18,19].

Nanoparticles also are resistance to high temperature and pressure and although few of them may cause migration of toxic material to foodstuff, other are containing essential micro-elements 
for human body [20]. Among applied NPs in food industries, copper NPs have played a major due to its antimicrobial and nutraceutical properties [21,22]. Multiple studies have been conducted on evaluation of antimicrobial properties of CuNPs using different percentages and also different matrixes namely HDPE, LDPE, Cellulose and etc $[23,24]$. Also physicochemical properties of copper nanopackaging such as thermal [25], mechanical [26], gas barrier properties as well as UV inhibition feature have been studied $[23,27]$.

Numerous reports have revealed that application of NPs in the surface of food contact materials e.g. packaging may lead to migration of NPs into foodstuff that, in turn, toxicity occurs $[9,28]$. Legislatives have determined specific amounts for migration of each NPs as a safe limit for human cells, however it has been also stated that bacterial cells consume low concentrations of copper as vital cofactors for enzymes and metalloproteins [29,30]. Therefore, many researchers focused on determination of this specific amount of NPs that not only exert antibacterial effects, but does not pass the legislative limitations. Therefore, the current mini-review focuses on evaluation of antibacterial properties and migration of copper NPs in food industry.

\section{Nano technology}

Molecules exhibit different characteristics when become in nanoscale [31]. In fact, nanotechnology changes the characteristics of elements by lowering the size of at least one dimension of $\mathrm{X}, \mathrm{Y}$ or $\mathrm{Z}$ to nano scale [32-34]. Two methods have been suggested for synthesizing of NPs; top-down that uses bulk materials and lysis procedure and bottom-up that uses molecules and particles to form NPs [35].

\section{Polymeric nanocomposites}

In Addition to reduction of wastes, polymeric nanocomposite can remarkably increase the shelf life of foodstuff. Due to low gas barrier properties and brittleness of biopolymers, addition of nonofillers is considered as one of the most effective ways to produce polymeric bionanocomposites that are capable of recycling and biodegradability [36]. Metallic nanoparticles such as $\mathrm{CaO}, \mathrm{MgO}, \mathrm{TiO}_{2}$ and are known due to their toxic nature against bacteria, yeast and few viruses. Although scientist have focused on application of silver nanoparticles against microbes, copper seems to be more effective due to lower price, simple synthesis and availability [37].

\section{Copper NPs}

Copper NPs are widely used as catalyzer, optical elements, antibacterial, antifungal, and conductive agents due to their physicochemical and biological unique characteristics [38]. $\mathrm{Cu}$ is considered as antibacterial agent more than a century since ancient Egyptians used cooper as water sterilization substance as well as disinfectant of wounds [39].

Synthesis of CuNPs is divided to 3 main methods: physical, chemical as well as biological methods. These methods are used via various procedures such as chemical reduction, thermal lysis, PolyOl method, microemulsion and etc. Although physical method synthesizes CuNPs of different shape, size and morphology, higher instrumentation and price is a limiting factor for this method of production. Therefore, application of chemical methods has been wide spread due to lower prices and simple instrumentation. Additionally, altering $\mathrm{pH}$, temperature, reducing agents and solvent can lead to formation of different particles in terms of size, shape, morphology and characteristics. Despite numerous advantages of CuNPs, toxicity of these NPs is a controversial topic that needs to pay more attention and more array of research should be carried out on this issue.

\section{Antimicrobial properties of Copper NPs}

Researches showed CuNPs can significantly mix with polymeric matrix and exert their biotechnological effects due to their high surface to volume ratio, reactivity and proper release characteristics [22]. Komeilynia., et al. (2013) evaluated of cotton-nylon-CuNPs nanocomposites using chemical reduction synthesizing method on S. aureus. Results showed that incorporation CuNPs particles could significantly reduce $S$. aureus load $(\mathrm{P}<0.01)$, although SEM and TEM analysis showed that the average size of synthesized nanoparticles were $85 \mathrm{~nm}$. additional physicochemical characteristics of produced nanocomposite (containing CuNPs) was improved significantly in comparison with blank samples $(\mathrm{P}<0.05)$ [40]. Also, Bikiaris., et al. (2013) conducted a study on investigation the effects of HDPE+Cunanofibers (0.5, 1 and 5\%) using melt mixing method. Results revealed that application of $\mathrm{Cu}$ NPs not only could significantly improve tensile strength, Young's modulus and oxygen barrier properties but antibacterial effects were significantly increased against Escherichia coli DHSa, Pseudomonas fluorescens BS3 and Staphylococcus aureus than that of lower HDDPE containing lower percentages of CuNPs (Figure 1) [41].

Arfat., et al. (2017) evaluated the effects of Guar Gum nanocomposites containing different percentages of CuNPs $(0.5$ - 2\%) particles, the thermo-mechanical, optical, spectral, oxygen barrier and antimicrobial properties of coatings were analyzed. Outcomes revealed that in agreement with Bikiaris., et al. (2013) and Komeilinia., et al. (2013), Strong antibacterial effects were shown by $\mathrm{Cu}$-Agar nano--coatings against both gram negative and Gram positive bacterial strains (Figure 2). Additionally, gas barrier properties and tensile strength also was remarkably improved (P $<0.05)$. 

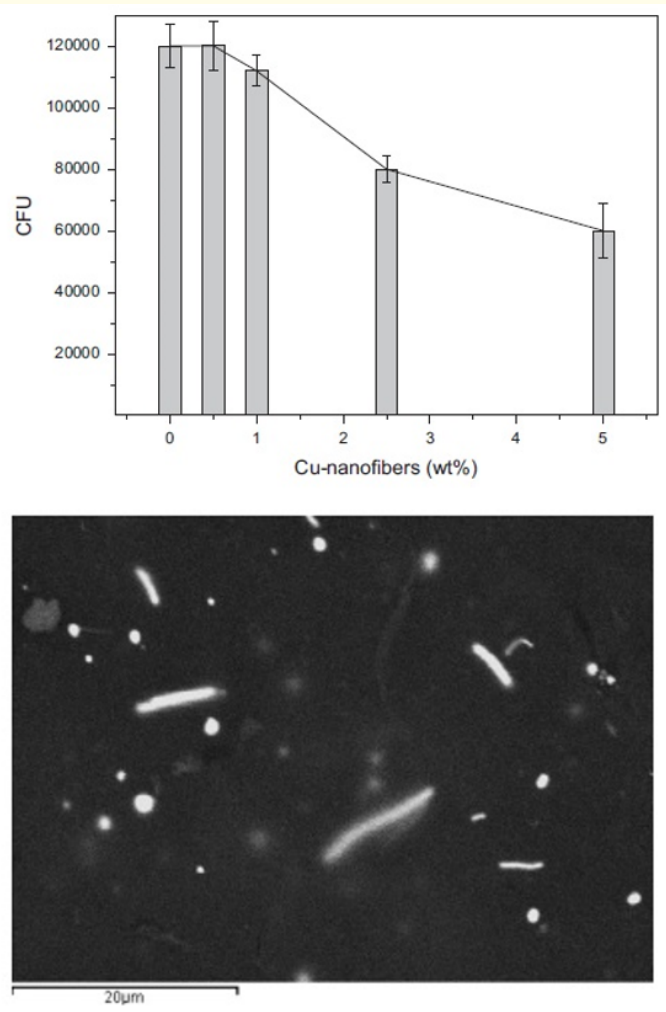

Figure 1: (a) SEM of Cu-Nanofibers implemented in HDPE (b) growth of bacterial colonies during 24 hours [41].

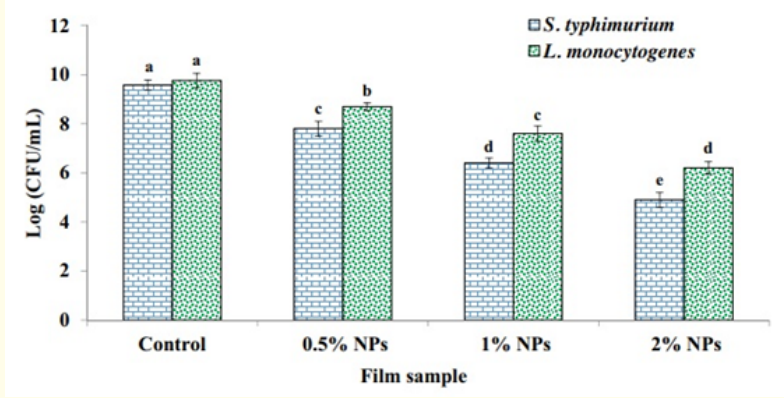

Figure 2: Effects of Agar-Cu coatings against S. typhimurium and L. monocytogenes [42].

\section{Migration of copper NPs}

Although advantages of nanotechnology has lead industries as well as people to use more nano materials, precise research is essential for determination of potential migration of nanoparticles of any concentration to packed material since there are some proved toxic effects for high concentration of migrated nanomaterial such as silver and copper [43]. Researches carried out on migration of nanoparticles are limited due to difficult analysis, expensive instruments and food matrix disturbances [44]. Determination of maximum migration is the major concern about migration of nanoparticles into foodstuff. Migration is determined as a mass transfer for particles with low molecular weight. Overall and specific migration tests have limitations for each foodstuff and these limitations are determined by EFSA and FDA. According to EFSA, migration test is determination of the release of packaging components to food or food stimulators [45]. Food stimulators are ethanol 10\%v/v, Acetic Acid 3\% v/v, ethanol 50\% v/v and etc. However, although there are numerous investigations on measurement of the migrated silver, clay titanium nanoparticles to foods stuff, there are very limited works on copper nanoparticles and more studies should be carried out $[43,46]$.

Liu., et al. (2016) measured migration of CuNPs from copper coated films using ethanol (10\%) and acetic acid (3\%) by ICP-MS and GFAAS. Results revealed that copper migration was remarkably lower in $10 \%$ ethanol despite migration ratio was lower than FDA limits [43].

\section{Conclusion}

Addition of metallic nanoparticle such as copper, due to their suitable physicochemical and antimicrobial properties has gain attentions recently. In fact, implementation of nanoparticle has addressed issues that bionanopolymers have been facing to for many years namely brittleness, gas barrier properties and toxic nature. Among different nano particle copper plays a major role due to its lower price, higher antimicrobial properties and simple instrumentation. However, according to the toxic nature of copper nanoparticles and toxicity that may cause illness and poisoning for human being, more studies should be carried out on migration of copper nanoparticles. In conclusion, application of copper nanoparticles in polymeric matrixes such as LPDE and HDPE for expensive and materials with high aw is suggested.

\section{Bibliography}

1. Prasad P., et al. "Active packaging in food industry: a review". IOSR Journal of Environmental Science, Toxicology and Food Technology 8.5 (2014): 1-7.

2. Del Nobile MA., et al. "Active packaging by extrusion processing of recyclable and biodegradable polymers". Journal of Food Engineering 93.1 (2009):1-6.

3. Tang X., et al. "Recent advances in biopolymers and biopolymer-based nanocomposites for food packaging materials". Critical Reviews in Food Science and Nutrition 52.5 (2012): 426-442.

4. Accorsi R., et al. "Economic and environmental assessment of reusable plastic containers: A food catering supply chain case study". International Journal of Production Economics 152 (2014): 88-101. 
5. Shah AA., et al. "Biological degradation of plastics: a comprehensive review". Biotechnology Advances 26.3 (2008): 246265.

6. Carole TM., et al. "Opportunities in the industrial biobased products industry". Proceedings of the Twenty-Fifth Symposium on Biotechnology for Fuels and Chemicals Held 4-7 (2003).

7. Muizniece-Brasava S., et al. "Consumer's knowledge and attitude to traditional and environmentally friendly food packaging materials in market of Latvia". The $6^{\text {th }}$ Baltic Conference on Food Science and Technology, Food Balt (2011).

8. Espitia PJP., et al. "Edible films from pectin: Physical-mechanical and antimicrobial properties-A review 35 (2014): 287296.

9. Haghighatpanah N., et al. "Optimization and characterization of pullulan produced by a newly identified strain of Aureobasidium pullulans". International Journal of Biological Macromolecules (2020).

10. Vaidya UR and Bhattacharya MJJoaps. "Properties of blends of starch and synthetic polymers containing anhydride groups" Wiley Online Library 52.5 (1994): 617-628.

11. Dufresne A and Vignon MRJM. "Improvement of starch film performances using cellulose microfibrils". 31.8 (1998): 2693-2696.

12. Tri PN., et al. "Crystallization behavior of poly (lactide)/poly ( $\beta$-hydroxybutyrate)/talc composites". Wiley Online Library 129.6 (2013): 3355-3365.

13. Battegazzore D., et al. "Crystallization kinetics of poly (lactic acid)-talc composites". 5.10 (2011): 849-858.

14. Luduena LN., et al. "Processing and microstructure of PCL/ clay nanocomposites". Materials Science and Engineering: A 460 (2007): 121-129.

15. Hosseini R., et al. "Measuring the migration of silver from silver nanocomposite polyethylene packaging based on $\left(\mathrm{TiO}_{2}\right)$ into penaeus semisulcatus using titration comparison with migration methods". Fisheries Science 83.4 (2017): 649-659.

16. Molefi J., et al. "Comparison of the influence of copper microand nano-particles on the mechanical properties of polyethylene/copper composites". Journal of Materials Science 45.1 (2010): 82.

17. Esthappan SK., et al. "Effect of crystallite size of zinc oxide on the mechanical, thermal and flow properties of polypropylene/zinc oxide nanocomposites". Composites Part B: Engineering 69 (2015): 145-153.
18. Ghelejlu SB., et al. "Characterization of chitosan-nanoclay bionanocomposite active films containing milk thistle extract". International Journal of Biological Macromolecules 86 (2016): 613-621.

19. Paisoonsin S., et al. "Preparation and characterization of $\mathrm{ZnO}$ deposited DBD plasma-treated PP packaging film with antibacterial activities". Applied Surface Science 273 (2013): 824835.

20. Bathinapatla A., et al. "Fabrication of copper nanoparticles decorated multiwalled carbon nanotubes as a high performance electrochemical sensor for the detection of neotame". Biosensors and Bioelectronics 67 (2015): 200-207.

21. Borkow G and Gabbay JJCmc. "Copper as a biocidal tool". Current Medicinal Chemistry 12.18 (2005): 2163-2175.

22. Anvar A., et al. "Evaluation of the antibacterial effects of AgTio2 nanoparticles and optimization of its migration to sturgeon caviar (Beluga)". Iranian Journal of Fisheries Sciences 18.4 (2019): 954-967.

23. Bikiaris DN and Triantafyllidis KSJML. "HDPE/Cu-nanofiber nanocomposites with enhanced antibacterial and oxygen barrier properties appropriate for food packaging applications". Materials Letters 93 (2013): 1-4.

24. Llorens A., et al. "Study of the antifungal potential of novel cellulose/copper composites as absorbent materials for fruit juices". International Journal of Food Microbiology 158.2 (2012):113-119.

25. Bruna J., et al. "Development of MtCu2+/LDPE nanocomposites with antimicrobial activity for potential use in food packaging". Applied Clay Science 58 (2012): 79-87.

26. Grigoriadou I., et al. "HDPE/Cu-nanofiber nanocomposites with enhanced mechanical and UV stability properties". Composites Part B: Engineering 55 (2013): 407-420.

27. Cárdenas G., et al. "Colloidal Cu nanoparticles/chitosan composite film obtained by microwave heating for food package applications". 62.4 (2009): 511-524.

28. De Azeredo HMC., et al. "Nanocomposites in food packaging-a review". Advances in diverse industrial applications of nanocomposites: In Tech (2011).

29. Santo CE., et al. "Contribution of copper ion resistance to survival of Escherichia coli on metallic copper surfaces". Applied and Environmental Microbiology 74.4 (2008): 977-986. 
30. Paidari S., et al. "Evaluation the Effects of Nanosilver Composites Synthesized using Sol-Gel Method on Inoculated Vibrio Parahaemolyticus to Pink Shrimp". Acta Scientific Nutritional Health 3.2 (2019): 47-51.

31. Roco MCJ Coib. "Nanotechnology: convergence with modern biology and medicine". Current Opinion Biotechnology 14.3 (2003): 337-346.

32. Tiede K., et al. "Detection and characterization of engineered nanoparticles in food and the environment". Food Additives and Contaminants. Part A, Chemistry, analysis, Control, Exposure and Risk Assessment 25.7 (2008): 795-821.

33. Jahadi M., et al. "Characterization of Milk Proteins in Ultrafiltration Permeate and Their Rejection Coefficients". Journal of Food Biosciences and Technology 8.2 (2018): 49-54.

34. Zamindar N., et al. "Antifungal activity of coriander (Coriandrum sativum L.) essential oil in tomato sauce". Journal of Food Measurement and Characterization 10.3 (2016): 589-594.

35. Huang J-Y., et al. “Technology. Safety assessment of nanocomposite for food packaging application". Trends in Food Science and Technology 45.2 (2015): 187-199.

36. Akbari Z., et al. "Improvement in food packaging industry with biobased nanocomposites”. 3.4 (2007).

37. Lloret E., et al. "Matrix effects on the antimicrobial capacity of silver based nanocomposite absorbing materials". LWT - Food Science and Technology 49.2 (2012):333-338.

38. Cioffi N., et al. "Copper nanoparticle/polymer composites with antifungal and bacteriostatic properties". Chemistry of Materials 17.21 (2005): 5255-5262.

39. Borkow G and Gabbay JJCCB. "Copper, an ancient remedy returning to fight microbial". Fungal and Viral Infections 3.3 (2009): 272-278.

40. Komeily-Nia Z., et al. "Synthesis of nano copper/nylon composite using ascorbic acid and CTAB". Colloids and Surfaces A: Physicochemical and Engineering Aspects 439 (2013): 167175.

41. Bikiaris DN and Triantafyllidis KS. "HDPE/Cu-nanofiber nanocomposites with enhanced antibacterial and oxygen barrier properties appropriate for food packaging applications". Materials Letters 93 (2013): 1-4.

42. Arfat YA., et al. "Deciphering the potential of guar gum/Ag-Cu nanocomposite films as an active food packaging material". Carbohydrate Polymers 157 (2017): 65-71.
43. Liu F., et al. "Migration of copper from nanocopper/LDPE composite films". Food Additives and Contaminants: Part A 33.11 (2016): 1741-1749.

44. Ozaki A., et al. "Contents of Ag and other metals in food-contact plastics with nanosilver or Ag ion and their migration into food simulants". Food Additives and Contaminants: Part A 33.9 (2016): 1490-1498.

45. Cushen M., et al. "Evaluation and simulation of silver and copper nanoparticle migration from polyethylene nanocomposites to food and an associated exposure assessment". Journal of Agricultural and Food Chemistry 62.6 (2014): 1403-1411.

46. Töpper M., et al. "A comparison of thin film polymers for wafer level packaging". 2010 Proceedings $60^{\text {th }}$ Electronic Components and Technology Conference (ECTC) (2010).

\section{Assets from publication with us}

- Prompt Acknowledgement after receiving the article

- Thorough Double blinded peer review

- Rapid Publication

- Issue of Publication Certificate

- High visibility of your Published work

Website: https://www.actascientific.com/ Submit Article: https://www.actascientific.com/submission.php Email us: editor@actascientific.com

Contact us: +919182824667 